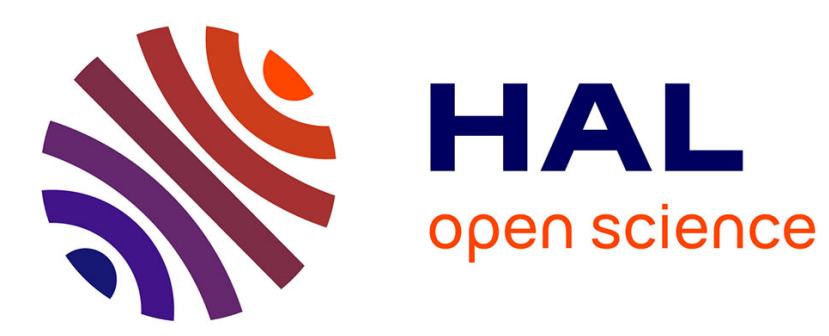

\title{
Numerical Methodology to Predict and Analyze Cavitating Flows in a Kaplan Turbine
}

\author{
Flavia Turi, Regiane Fortes Patella, Guillaume Balarac
}

\section{To cite this version:}

Flavia Turi, Regiane Fortes Patella, Guillaume Balarac. Numerical Methodology to Predict and Analyze Cavitating Flows in a Kaplan Turbine. International Journal of Fluid Machinery and Systems, 2019, 12, pp.1882 - 9554. 10.5293/IJFMS.2019.12.4.439 . hal-02470019

\section{HAL Id: hal-02470019 https://hal.science/hal-02470019}

Submitted on 6 Feb 2020

HAL is a multi-disciplinary open access archive for the deposit and dissemination of scientific research documents, whether they are published or not. The documents may come from teaching and research institutions in France or abroad, or from public or private research centers.
L'archive ouverte pluridisciplinaire HAL, est destinée au dépôt et à la diffusion de documents scientifiques de niveau recherche, publiés ou non, émanant des établissements d'enseignement et de recherche français ou étrangers, des laboratoires publics ou privés. 


\title{
Original Paper
}

\section{Numerical Methodology to Predict and Analyze Cavitating Flows in a Kaplan Turbine}

\author{
Flavia Turi $^{1}$, Regiane Fortes-Patella ${ }^{1}$ and Guillaume Balarac ${ }^{1}$ \\ ${ }^{1}$ Univ. Grenoble Alpes, Grenoble INP, CNRS, LEGI F-38000 Grenoble, France, \\ flavia.turi@legi.grenoble-inp.fr, regiane.fortes@legi.grenoble-inp.fr, guillaume.balarac@legi.grenoble-inp.fr
}

\begin{abstract}
A computational methodology to predict the cavitation phenomena appearance and evolution in a 5-blades Kaplan turbine scale model was developed. Two different inlet boundary conditions have been tested in both non-cavitating and cavitating regimes: the classical one, the mass flow rate and the new one, the total pressure. The best results were obtained applying a constant total pressure on the inlet. The torque and efficiency drop curves were well-predicted with the proposed calculation methodology and the numerical cavitation structures agreed with experimental observations. Indeed, this new inlet boundary condition allows to keep the machine head constant during the cavitation drop, as in experiments. Unsteady simulations are under investigation to improve the prediction and the analyses of more developed cavitating regimes.
\end{abstract}

Keywords: Cavitation, Axial Turbine, CFD model, RANS simulations, Homogeneous flow, Barotropic law.

\section{Introduction}

Nowadays, the continue diminution of the non-renewable fossil energy and the exigency to reduce the greenhouse gas emission has boosted the development of hydraulic machines, as Kaplan turbines. The peculiarity of these machines is the flexibility: the guide vane opening and the runner blade position can be continuously regulated during machine operation to maximize the efficiency for a large range of operating conditions. However, this implies the presence of shroud and hub gaps that leads to cavitation phenomena in the runner. Vapour structures can cause several structural damages and changes on the turbine efficiency. For these reasons, the development of a numerical procedure able to characterize the cavitation phenomena inside the turbines and to predict their impact on the machine performances is of great industrial interest.

Numerical studies of cavitating flows in hydraulic machineries have been usually performed using a homogeneous flow approach coupled with cavitating models for the liquid/vapour mixture, such as the barotropic law [1] or Rayleigh-Plesset based models, as the Shingal [2] and the Zwart [3] models. In the case of Kaplan turbines, a study using a Rayleigh- Plesset based model has been proposed by Leguizamón et al. [4]. RANS equations have been solved on reduced computational domains, including a single interblades channel of the distributor and the runner. A similar approach has been used to simulate a complete machine in steady and unsteady conditions by Jošt et al. [5]. Contrary to the laboratory tests, where the machine head is usually imposed as constant in the cavitation breakdown investigations.in those simulations, the machine head is not controlled. This results in some mismatch between numerical predictions and experimental observations.

In this context, the aim of the present investigation is to develop a numerical methodology able to improve the prediction of the evolution of cavitating flows inside a Kaplan turbine. The analysis refers to a scale model of a Kaplan turbine consisting of five blades, tested in the GE Renewable Energy laboratory in Grenoble (France). The three-dimensional RANS equations have been solved with the commercial code FINETM/Turbo, which applies a homogeneous approach and a barotropic state law, developed in the laboratory LEGI to model the cavitating flows [1]. Preliminary simulations have been run on a full-periodic single interblades channel comprising the guide vane, the runner and the cone. At first, the machine operating point has been fixed in non-cavitating regime, iteratively varying the inlet mass flow rate to target the experimental torque value. Subsequently, cavitation calculations have been performed with the founded mass flow rate as inlet boundary condition. Afterwards, the numerical domain has been extended including the draft tube in order to consider in the analysis its influence on the flow and, consequently, on the numerical cavitation predictions. At last, the total pressure has been imposed on the inlet instead of the mass flow rate, fixing the machine head. This has allowed to perform calculations in the same conditions than the experiments.

The article is structured as follows: the section 2 describes the theoretical models applied to simulate cavitation and turbulence phenomena inside the turbine. The tested calculation methodologies are discussed in section 3. Simulations have been performed on two computational domains and different inlet boundary conditions have been tested. The main global and local numerical results are 
presented in section 4, where comparative studies with experiments are also proposed to validate the numerical approaches and to select the best methodology. Finally, the investigation conclusions are presented.

\section{Theoretical models}

The modeling of a two-phase flow inside a turbomachinery is complex and presents very high computational cost.

An alternative approach, proposed by Ishii et al. [6], consists to consider the cavitating flow as a homogeneous mixture of liquid and vapor. The homogeneous approach relays on the hypothesis that the mixture density $\rho$ changes in the flow field between the vapor density $\rho_{V}$ and the liquid density $\rho_{L}$ as a function of the equivalent void ratio of the liquid-vapor mixture according to eq. (1).

$$
\rho=\alpha \rho_{V}+(1-\alpha) \rho_{L}
$$

Assuming that the pure phases in the mixture are incompressible and share the same instantaneous velocity, pressure and turbulence fields, only one set of RANS equations can be used to describe the flow motion. However, a model for the cavitating flow and for the averaged Reynold's stress terms is required to close the governing equations.

\subsection{Cavitation model}

The cavitation model used in this work is the barotropic law. This approach has been initially proposed by Delannoy and Kueny [1] and is largely used to predict cavitation phenomena in pumps, e.g. see Refs. [7, 8, 9]. In this formulation, the evolution of the mixture density $\rho$ and the local static pressure $P$ are strongly linked via a barotropic state law $\rho=\rho(P)$, shown in Fig. 1 .

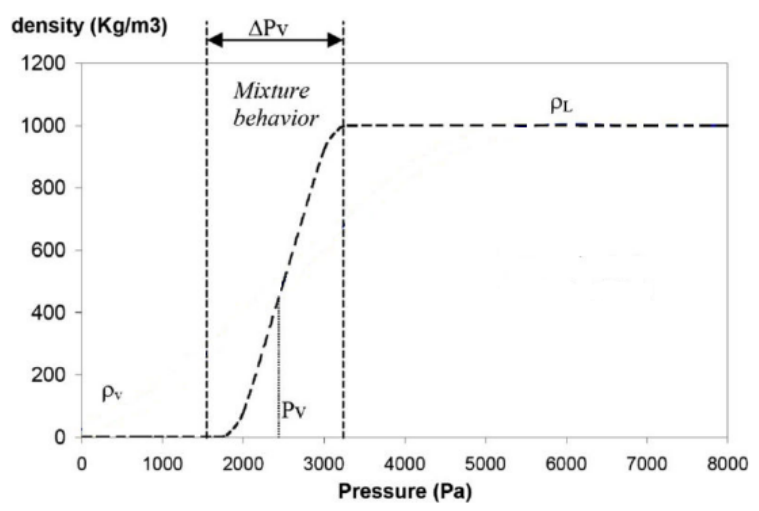

Fig. 1 Barotropic law $\boldsymbol{\rho}=\boldsymbol{\rho}(\boldsymbol{P})$

When the pressure is higher or lower than the vapor pressure $P_{V}$, the fluid is supposed to be purely liquid or purely vapor. In the mixture region, $P_{V}-\Delta P<P<P_{V}+\Delta P$, where rapidly varies between the liquid density $\rho_{L}$ and the vapor density $\rho_{V}$, a sinusoidal function is used to describe the mixture density, defined as:

$$
\rho=\frac{\rho_{L}+\rho_{V}}{2} \frac{\rho_{L}-\rho_{V}}{2} \sin \left(\frac{P-P_{V}}{A_{\min }^{2}}\right)
$$

In the eq. (2), the parameter Amin represents the slope of this evolution law defined as:

$$
A_{\text {min }}=\sqrt{\frac{\rho_{L}-\rho_{V}}{2} c_{\min }^{2}}
$$

where $c_{\min }$ is the minimal value of the sound velocity in the liquid-vapor mixture. Following previous studies [10, 11], for cold water $c_{\min }$ is assumed to be equal to $1 \mathrm{~m} / \mathrm{s}$, the density ratio between the vapor and the liquid phase is set to 0.01 and the coefficient $A_{\min }$ is equal to 23.

\subsection{Turbulence model}

The turbulence model used in this work is the well-known k- $\omega$ SST, presented the first time by Menter et al. [12]. This model combines the k- $\omega$ approach in the boundary regions and the k- $\varepsilon$ in the free stream flow. The choice of the turbulence model imposes limitation in the wall mesh sizing. In order to capture the viscous sublayer, the dimensionless wall distance $\mathrm{y}+$ must be less than 10 in the first node from the wall [13].

\section{Numerical methodology}

The numerical methodology developed to predict the cavitating flow behavior and its effect on the turbine performance will be now presented. The methodology applies the commercial code FINE ${ }^{\mathrm{TM}} /$ Turbo and has been validated by experimental data furnished by the GE Renewable Energy Laboratory in Grenoble (France). 
Cavitating $(C A V)$ and non-cavitating $(N C A V)$ calculations are steady and concern operating conditions (mass flow $Q$, turbine head $H$, and torque $T$ ) near to the Best Efficiency Point (BEP).

\subsection{Calculation domains}

The investigated machine is a reduced-scale Kaplan turbine developed and tested at the GE Renewable Energy Laboratory in Grenoble (France). The turbine has a 24-guide vanes distributor and a 5-blades runner. Two partial computational domains have been considered in the numerical analyses:

(i) The first domain, $D_{l}$, shown in Fig. 2, includes a single interblades channel consisting of the guide vane, the runner blade and the cone. Periodic boundary conditions are imposed to simulate the entire machine.

(ii) The second domain, $D_{2}$, illustrated in Fig. 3, includes the domain $D_{1}$ and the draft tube.

Table 1 Mesh characteristic of the numerical domain $\boldsymbol{D}_{1}$

\begin{tabular}{ccccc}
\hline Component & Number of elements & Min.skewness & Max. expansion ratio & ymean $^{+}$ \\
\hline Guide vane & $0.8 \mathrm{M}$ & $44^{\circ}$ & 1.7 & 1 \\
Runner & $8.1 \mathrm{M}$ & $9^{\circ}$ & 4.5 & 1.6 \\
Cone & $4.7 \mathrm{M}$ & $15^{\circ}$ & 1.8 & 1.1 \\
\hline Total & $13.6 \mathrm{M}$ & & & 1.2 \\
\hline
\end{tabular}

Table 2 Mesh characteristic of the numerical domain $\mathbf{D}_{2}$

\begin{tabular}{ccccc}
\hline Component & Number of elements & Min.skewness & Max. expansion ratio & ymean $^{+}$ \\
\hline Guide vane & $0.8 \mathrm{M}$ & $44^{\circ}$ & 1.7 & 1 \\
Runner & $8.1 \mathrm{M}$ & $9^{\circ}$ & 4.4 & 2 \\
Cone & $5.9 \mathrm{M}$ & $18^{\circ}$ & 1.8 & 8.7 \\
\hline Total & $14.8 \mathrm{M}$ & & & 8.5 \\
\hline
\end{tabular}

The tip and hub clearances, typical of Kaplan turbines, are considered in all calculations since well description of the flow through these gaps is fundamental to determine the behavior of the hub and the blade tip cavitation regions. Mixing planes separate rotor and stator parts, as indicated in both Fig. 2 and Fig. 3. To reduce the computational costs, the semi-spiral casing has not been taken into account in the calculation domain. The velocity profiles at the outlet of the spiral casing were evaluated from complementary experimental and numerical studies carried-out previously. Those results have been applied as boundary conditions at the guide vane inlet (see Section 3.2). The numerical domains have been discretized by a fully-structured mesh approach involving only hexahedral cells, by means of the Numeca software AutoGrid 5. Mesh optimization studies have been performed on both numerical domains. Starting from very coarse meshes, the elements have been increased until to obtain a mesh level adequate for the purposes of this work. The principal characteristics of the resulted meshes are reported in Tab.1 for $D_{1}$ and in Tab.2 for $D_{2}$. The quality of the discretization has been evaluated by the skewness (i.e. the cells orthogonality) and the expansion ratio (i.e. the ratio between two neighboring cells volumes).

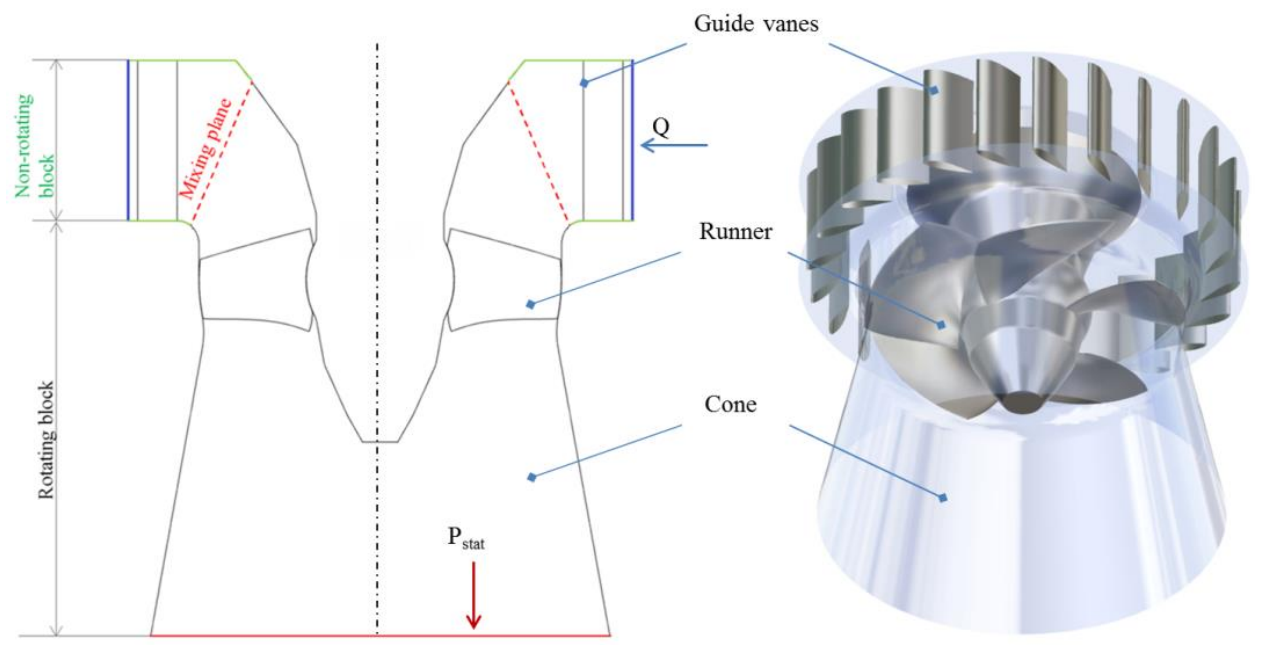

Fig. 2 Numerical domain $D_{l}$ with the used boundary conditions. On the left: meridional view and on right: $3 \mathrm{D}$ view. The inlet is in blue and the outlet is in red. 


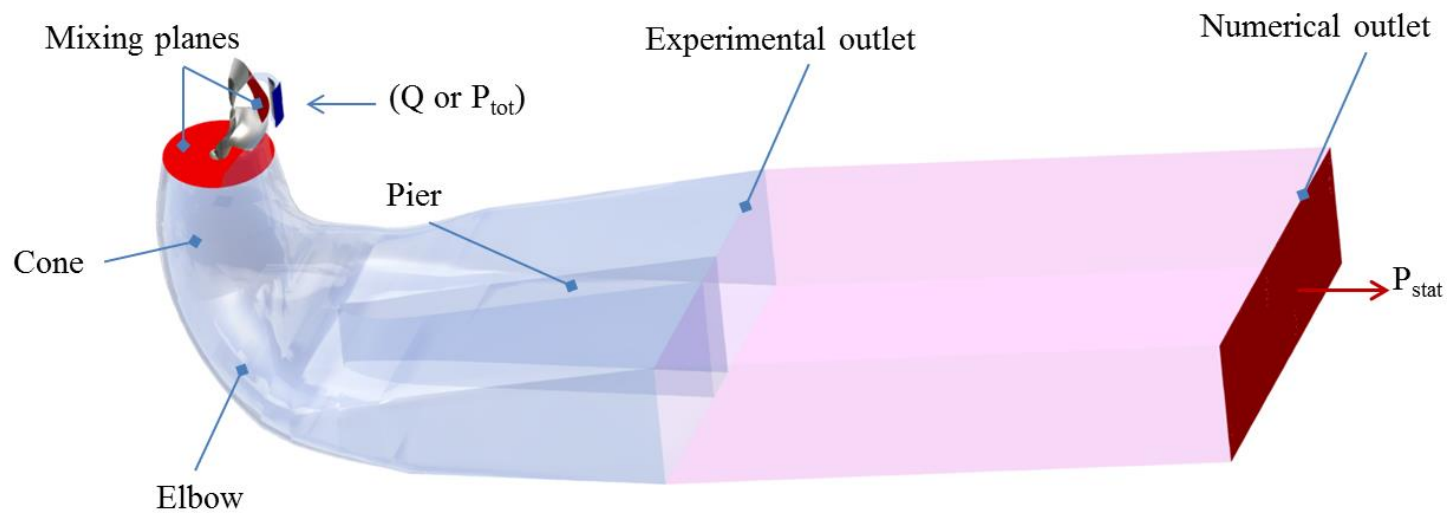

Fig. 3 Numerical domain $D_{2}$ with the used boundary conditions. The inlet is in blue and the outlet in red.

\subsection{Inlet and outlet boundary conditions strategies}

\subsubsection{Non-cavitating conditions}

To define a numerical methodology able to predict cavitating phenomena in the analyzed system, the first step has been to ensure a correct numerical reproduction of the turbine operating point in non-cavitating conditions. The operating points of a turbine are usually defined by the mass flow, $Q$, the head, $H$ and the torque, $T$. Classical boundary conditions have been initially applied on the domain $D_{l}$ imposing inlet mass flow and outlet static pressure (Fig. 2). Assuming an uniform flow at the distributor inlet section, Sin, and at the draft tube outlet section, $S_{\text {out }}$, the experimental value of the turbine head $H_{\text {exp }}$ is evaluated by:

$$
H_{\text {exp }}=\frac{\left(P_{\text {in }}-P_{\text {out }}\right)}{\rho g}+\frac{1}{2 g}\left(\frac{Q}{\rho}\right)^{2}\left(\frac{1}{S_{\text {in }}^{2}}-\frac{1}{S_{\text {out }}^{2}}\right)
$$

where $P_{\text {in }}$ and $P_{\text {out }}$ are the pressures measured at the sections $S_{\text {in }}$ and $S_{\text {out }}$, respectively. In the considered numerical domains, the positions of the inlet and the outlet sections differ from the experimental setup so the computed and measured heads cannot be directly compared. To obtain a reliable agreement between experimental and numerical results, preliminary iterative simulations in non-cavitating regime have been performed on domain $D_{l}$, varying the inlet mass flow rate to target the experimental value of the torque. This parameter has been chosen in order to obtain a fluid dynamic agreement with experiments since the torque is strictly linked to the flow incidence on the runner blade. A reduced difference between experimental and numerical torques ensures the correct reproduction of the work of the turbine.

Applying this procedure, a mismatch between measured and computed torque less than $1 \%$ was achieved, with an acceptable discrepancy of the $2.5 \%$ between experimental and numerical mass flow rate (see Tab. 3 ). For clarity reasons, the obtained mass flow rate will be referred as $Q_{c o r}$ to distinguish it from the experimental value $Q_{\text {exp }}$.

\subsubsection{Cavitating conditions}

In cavitating regime, two inlet boundary conditions have been tested and compared on the domains $D_{1}$ and $D_{2}$ (as reported in Fig. 2):

(i) The $Q_{\text {cor }}$, coupled with computed velocity profiles coming from the stay ring;

(ii) The total pressure, $P_{\text {tot }}$, calculated from the previous simulation on the domain $D_{2}$. This inlet boundary condition allows to fix the machine head and let the mass flow rate varying with the cavitation development (during cavitation breakdown laboratory tests, the mass flow rate could change of almost $0.5 \%$ for the considered operating point).

In all of the performed simulations, a fixed static pressure equal to the ambient pressure is imposed on the outlet, and the cavitation phenomena have been introduced increasing the relative vapor pressure $P_{V}$.

\section{Analysis of the results}

\subsection{Simulations in non-cavitating regime}

Table 3 summarizes numerical global results obtained in non-cavitating conditions on both the computational domain $D_{1}$ and $D_{2}$. Firstly, considering the methodology presented in the section 3.2, the inlet mass flow rate has been iteratively tuning on the $D_{l}$ in order to achieve $\mathrm{T}_{\text {num }} \approx \mathrm{T}_{\text {exp. Subsequently, the obtained mass flow value }} \mathrm{Q}_{\text {cor }}$ has been imposed as inlet on the domain $D_{2}$. The presence of the draft tube has produced a reduction of the torque value. Nevertheless, the discrepancy between the computed and measured torque values is less than $1.5 \%$, considered acceptable. 
Table 3 Comparison between experimental data and results in non-cavitating regime on $D_{1}$ and $D_{2}$.

\begin{tabular}{cccc}
\hline $\begin{array}{c}\text { Computational } \\
\text { domain }\end{array}$ & Inlet BC & $\Delta \boldsymbol{Q}=\frac{\left(\boldsymbol{Q}_{\text {exp }}-\boldsymbol{Q}_{\text {num }}\right)}{\boldsymbol{Q}_{\text {exp }}}$ & $\Delta \boldsymbol{T}=\frac{\left(\boldsymbol{T}_{\text {exp }}-\boldsymbol{T}_{\text {num }}\right)}{\boldsymbol{T}_{\text {exp }}}$ \\
\hline $\mathbf{D}_{\mathbf{1}}$ & $\mathrm{Q}_{\text {exp }}$ & $0 \%$ & $13 \%$ \\
& $\mathrm{Q}_{\text {cor }}$ & $2.5 \%$ & $<1 \%$ \\
\hline $\mathbf{D}_{2}$ & $\mathrm{Q}_{\text {cor }}$ & $2.5 \%$ & $<1.5 \%$ \\
\hline
\end{tabular}

\subsection{Global performance analysis in cavitating regime}

Generally, the evolution of the machine performances with the cavitation development is evaluated by the $\sigma$-break curve. This curve represents the machine efficiency $\eta$ as function of the Thoma number $\sigma$, respectively defined as:

$$
\begin{gathered}
\eta=\frac{T \omega}{g H Q} \\
\sigma=\frac{N P S H}{H}
\end{gathered}
$$

In the $\sigma$ definition (eq. (6)), the NPSH represents the net positive suction head. As the head, the experimental evaluation of the NPSH depends on the position of the considered domain outlet section:

$$
N P S H_{\text {exp }}=\frac{\left(P_{\text {out }}-P_{V}\right)}{\rho g}+\frac{1}{2 g}\left(\frac{Q}{\rho S_{\text {out }}}\right)^{2}
$$

In the case of the simulations performed on the domain $D_{l}$, a direct comparison between numerical and experimental NPSH values is not ensured. The machine efficiency is function of the torque, $T$, the machine head, $H$, the mass flow rate, $Q$ and the rotational speed, $\omega$.

Considering that $\omega$ is constant, the $\sigma$-break curve can be determined by the evolution of the $T$, the $H$ and the $Q$ as function of the Thoma number value. Experimentally, a decrease of the torque with the cavitation development (corresponding to the reduction of the $\sigma$ value) has been observed. Three different computational strategies, presented in Tab.4, have been tested in order to simulate the torque drop under similar conditions to experiments. The numerical predictions of the torque are compared with experimental data in Fig. 4(a).

Table 4 Performed calculation strategies

\begin{tabular}{cccccc}
\hline Strategy & $\begin{array}{c}\text { Computational } \\
\text { domain }\end{array}$ & Inlet BC & Outlet BC & $\Delta \boldsymbol{H}_{\max }=\frac{\left(\boldsymbol{H}_{\max }-\boldsymbol{H}_{N C A V}\right)}{\boldsymbol{H}_{N C A V}}$ & $\Delta \boldsymbol{Q}_{\max }=\frac{\left(\boldsymbol{Q}_{\max }-\boldsymbol{Q}_{N C A V}\right)}{\boldsymbol{Q}_{N C A V}}$ \\
\hline $\mathbf{A}$ & $\mathrm{D}_{1}$ & $\mathrm{Q}_{\text {cor }}$ & $\mathrm{P}_{\text {stat }}$ & $\mathbf{1 . 3 \%}$ & $\mathbf{0 \%}$ \\
$\mathbf{B}$ & $\mathrm{D}_{2}$ & $\mathrm{Q}_{\text {cor }}$ & $\mathrm{P}_{\text {stat }}$ & $\mathbf{2 \%}$ & $\mathbf{0 \%}$ \\
$\mathbf{C}$ & $\mathrm{D}_{2}$ & $\mathrm{P}_{\text {tot }}$ & $\mathrm{P}_{\text {stat }}$ & $\mathbf{0 . 1 \%}$ & $\mathbf{0 . 5 \%}$ \\
\hline
\end{tabular}

( $H_{\max }$ and $Q_{\max }$ are the maximum difference between computed and measured values during the cavitation development)

(a)

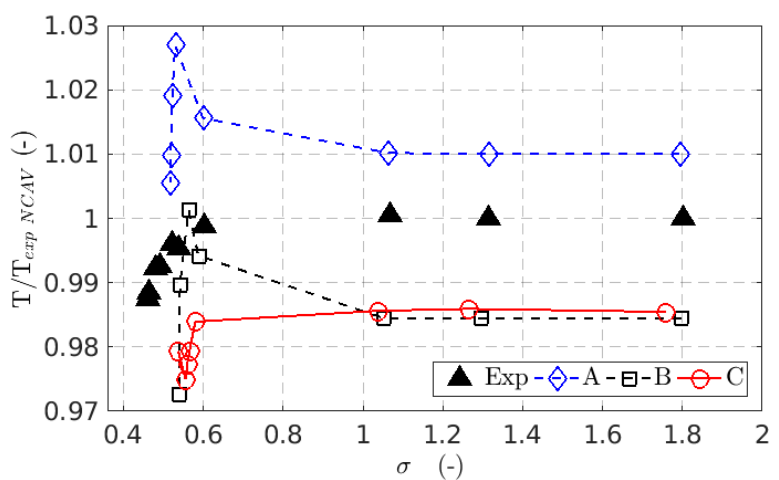

(b)

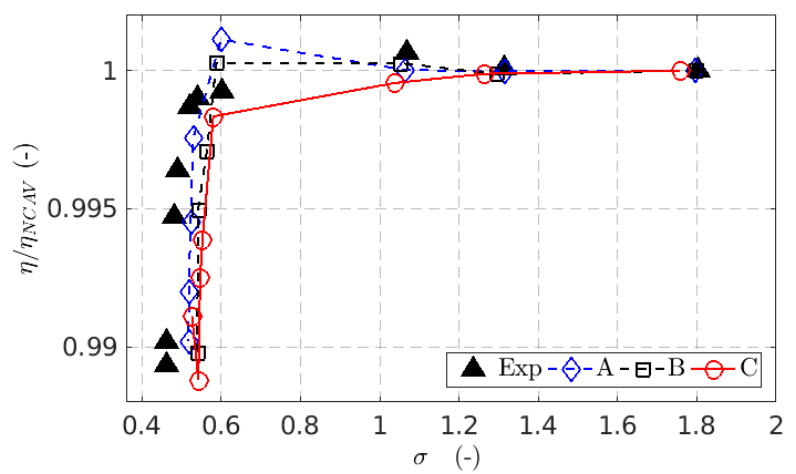

Fig. 4 (a) Normalized torque evolutions as function of $\sigma$ and (b) $\sigma$ - break curves. Experimental measurements are reported with black triangles. Numerical predictions obtained with A strategy are reported with blue diamonds and the dashed line; with B strategy are indicated with dashed black line and squares; with $\mathrm{C}$ methodology are shown with the red line and the circle symbols. 
In simulations performed with the mass flow rate as inlet boundary condition (A and B), the head $H$ changes with the increase of the cavitation in the machine, influencing the $\sigma$-break curve. Indeed, in these cases, numerical and experimental operating conditions are not really comparable and, as a consequence, the relative computed torque evolutions do not agree with experimental results for reduced values. At $\sigma_{S}=0.60$ (experimental efficiency drop beginning point) the torque starts to increase reaching a peak at $\sigma=0.55$. For calculation A, the mismatch between numerical and experimental torque in this point is $3.5 \%$. Using strategy $\mathrm{B}$, this discrepancy is reduced to $1.5 \%$, due to the introduction of the draft tube in the computational domain. After $\sigma=0.55$, the computed curves decrease more quickly, reaching the minimum for higher $\sigma$ values than the experimental one.

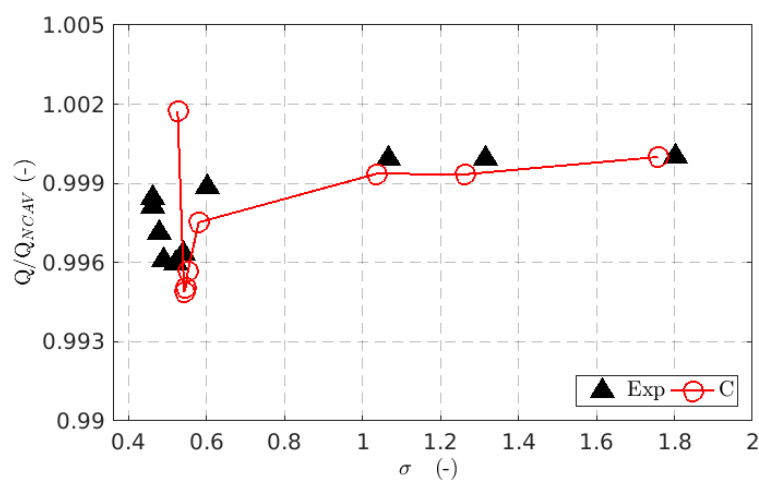

Fig. 5 Normalized mass flow evolutions as function of $\sigma$. Experimental measurements are reported with black triangles. Numerical predictions obtained with $\mathrm{C}$ methodology are plotted by the red line and the circle symbols.

More reliable comparisons can be obtained applying the $\mathrm{C}$ strategy, where the total pressure is considered as inlet boundary condition on the computational domain $D_{2}$. This methodology allows to numerically reproduce experimental test conditions: contrarily to case A and $\mathrm{B}$, the $H$ is almost constant while the $Q$ (Fig. 5) changes with the cavitation development, following the experimental curve tendency. As a consequence, the results obtained in case $\mathrm{C}$ are in better quantitative and qualitative agreement with measured data. The maximum discrepancy between numerical and experimental torque is smaller than $1.5 \%$. The numerical torque drop beginning point is very close to the experimental one (at $\sigma_{\mathrm{s}}=0.58$ ). The relative torque reduction is correctly predicted until $\sigma=0.55$, that correspond to an efficiency drop of $1 \%$. For smaller Thoma numbers, the cavitating flow becomes unstable and the steady approach applied in this work is no longer suitable. Thus, unsteady calculations should be carried out to improve the predictions and to analyse cavitating flows corresponding to the smallest values. Figure 4(b) presents experimental and computed non-dimensional $\sigma$-break curves. All of the numerical results seem to be in good agreement with the experiments but the analysis of the efficiency drop curves is biased by cross-variations in $H, Q$, and $T$.

\subsection{Cavitating flow analysis}

The numerical methodology $\mathrm{C}$ has been validated comparing numerical and experimental cavities for two points of the computed $\sigma$-break curve: $\sigma_{\mathrm{S}}=0.58$, the efficiency start drop point and $\sigma_{-0.5} \%=0.56$ that correspond to a reduction of the efficiency value of $0.5 \%$.

(a)

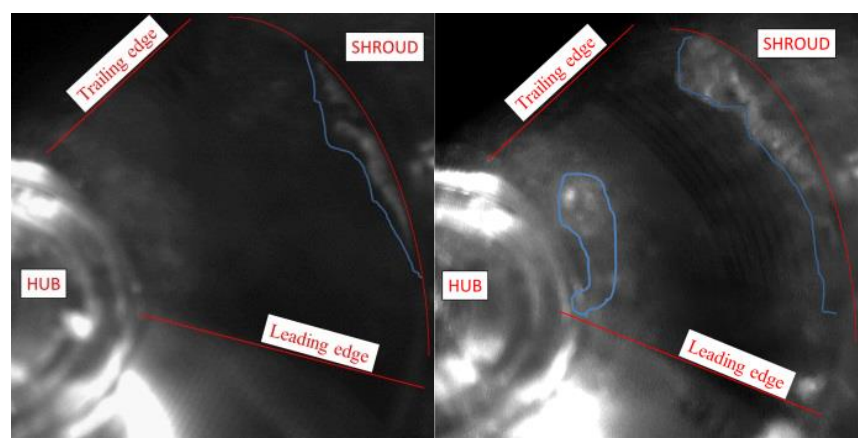

(c)

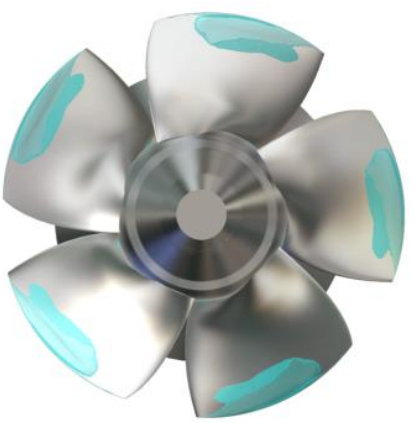

(d)

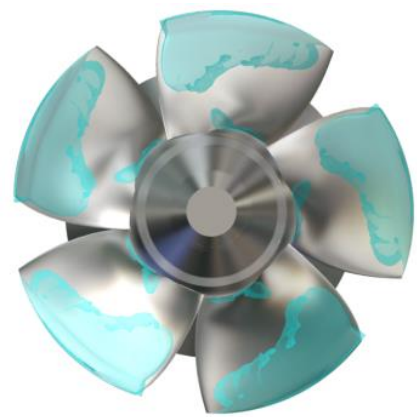

Fig. 6 Frontal view of: Experimental observations at $\sigma_{S}=0.60$ (a) and at $\sigma_{-0.5 \%}=0.48$ (b);

Computed iso-density surfaces $\left(\rho=980 \mathrm{~kg} / \mathrm{m}^{3}\right)$ at $\sigma_{\mathrm{S}}=0.58(\mathrm{c})$ and at $\sigma_{-0.5 \%}=0.56(\mathrm{~d})$

Experimentally, two vapour structures have been observed in the flow:

(i) An attached cavitation sheet appears near the shroud at $\sigma_{\mathrm{S}}=0.60$ (Fig. 6(a)). It increases from the leading edge (LE) to the trailing edge (TE), covering the whole tip extension at $\sigma_{-0.5 \%}=0.48$ (Fig. $6(\mathrm{~b})$ );

(ii) A vapour structure starts from the LE near the runner hub, extending along the blade root in the opposite direction to the runner rotation at $\sigma_{-0.5 \%}=0.48$ (Fig. $6(\mathrm{~b})$ ). 
The cavities structures computed for the two points are reported in Fig. 6(c)-(d), respectively and they are in a good qualitative agreement with experimental visualizations. The cavities situated on the blade tip and near the hub are well-predicted at $\sigma_{\mathrm{S}}=0.58$ and extend along the profile to the trailing edge at $\sigma_{-0.5 \%}=0.56$.

\subsection{Blade loading analysis}

The static pressure distributions around the blade for different values have been analyzed to investigate the influence of the cavitation on the pressure fields and, consequently, on the torque.

Figure 7 shows the different sections considered for the study of the pressure profiles: a section near the hub (1\% of the blade height), the mid-span plane (50\% of the blade height) and a section near the shroud (95\% of the blade height). The blade loads at different planes are drawn in Fig. 8 in non-cavitating regime (blue line with the diamonds), at $\sigma_{\mathrm{S}}=0.58$ (black dashed line with squares) and at $\sigma_{-0.5 \%}=0.56$ (red line with the circles).

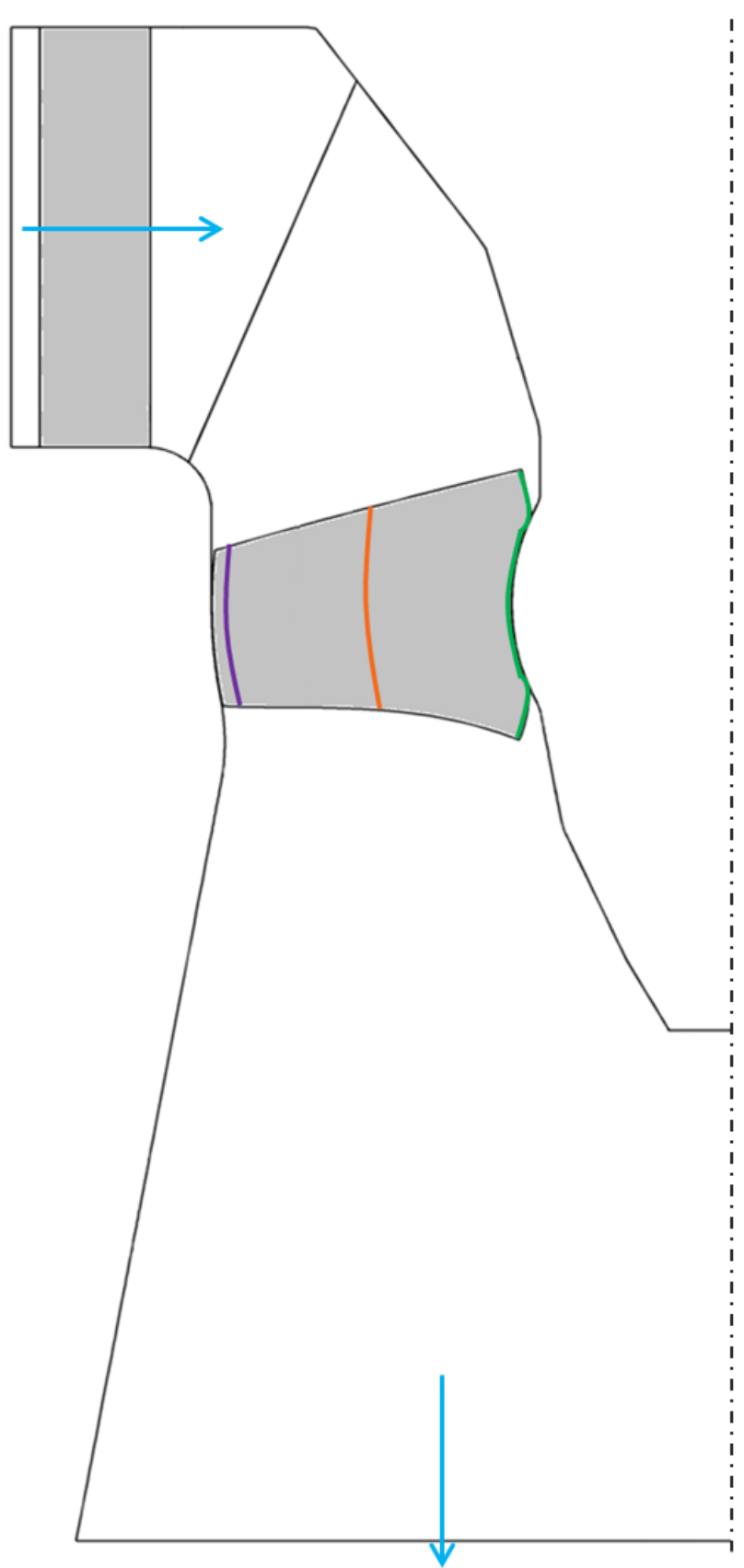

Fig. 7 Blade sections at $1 \%$ (green line), $50 \%$ (orange line) and 95\% (purple line) represented in the meridian view considered for the pressure profiles analysis. (a)

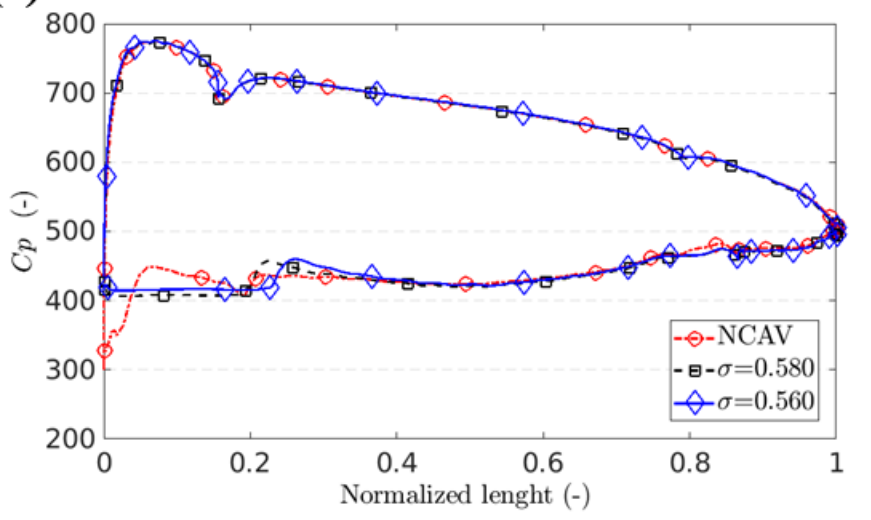

(b)

$50 \%$
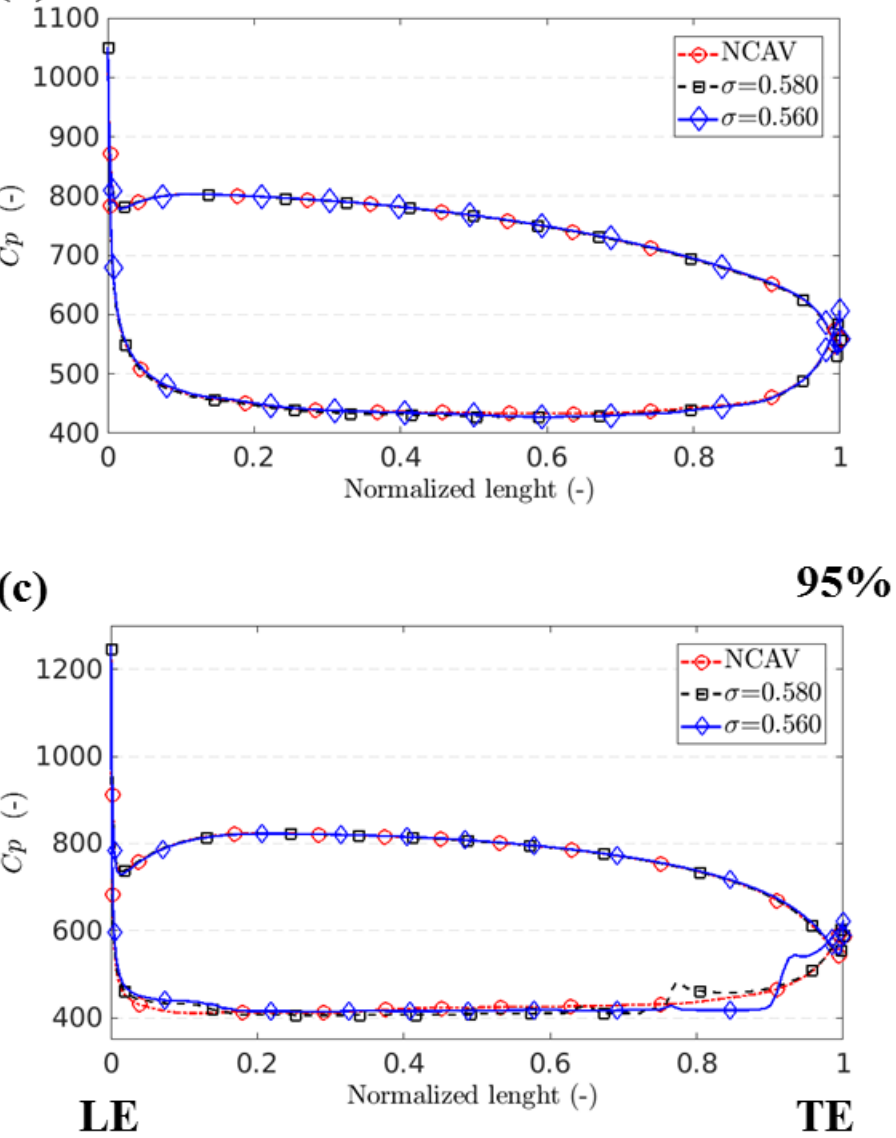

Fig. 8 Pressure distribution around the blade for decreasing $\sigma$ values (a) near the hub $1 \%$, (b) at midspan $50 \%$ and (c) near the shroud $95 \%$. LE=leading edge and $\mathrm{TE}=$ trailing edge. 
The static pressure has been plotted using the normalized pressure coefficient, $C_{P}$, defined in eq. (8).

$$
C_{p}=\frac{P-P_{V}}{\frac{1}{2} \rho(\omega R)^{2}}
$$

According to the cavitating flow analysis for considered Thoma numbers, the presence of the cavitation in the runner does not influence the blade loading at mid-span (Fig. 8(b)). Indeed, the observed cavitation phenomena are mostly concentrated on the tip and on the root of the blade. Close to the shroud, the loading is slightly modified at the blade leading edge (Fig. 8(c)). The cavitation influence is more perceptible at the trailing edge, leading to a decrease of the runner work in this region. These analyses agree well with cavities visualizations shown in Fig. 6. Perturbations of the leading edge pressure distribution can be observed also near the hub. The load reduction is observed when the cavitation appears on the blade root, close to the leading edge of the blade suction side (Fig. 8(a)). These progressive alterations of the blade loading on the hub and near the shroud leads to a gradual decrease of the machine torque, T, (Fig. 4(a)), comparing to the non-cavitating case. Modification of the pressure loading on the blade pressure side is not observed with the $\sigma$ reduction.

\subsection{Losses analysis}

The investigation of the cavitation influence on the turbine could be finally completed comparing the losses evolution with the Thoma number reduction. The head $H$ can be also determined as the sum of the losses in each part of the machine, $\Delta$ los, and the energy transferred to the turbine, $\mathrm{H}_{\mathrm{i}}$ :

$$
H=\Delta_{l o s}+H_{i}=\Delta_{l o s}^{G V}+\Delta_{l o s}^{r u n}+\Delta_{l o s}^{D T}
$$

The losses in the static parts (i.e. the guide vanes ring and the draft tube) are computed as the difference of the total pressure while in the rotating parts (i.e. the runner) are evaluated as the difference of the rothalpy between the inlet and the outlet of the considered section.

The difference between the net head values computed in non-cavitating regime and at $\sigma_{-1} \%$ is less than $0.1 \%$. On the contrary, the percentage of $\Delta_{\text {los }}$ and $\mathrm{H}_{\mathrm{i}}$ has been changed (Fig. 9(a)): at $\sigma_{-1 \%}$ the energy transferred to the turbine has been reduced of the $1 \%$ while the losses have been increased of the same amount. In Fig. $9 \mathrm{~b}$ are plotted the contributions to the total losses furnished by each component of the machine.

(a)

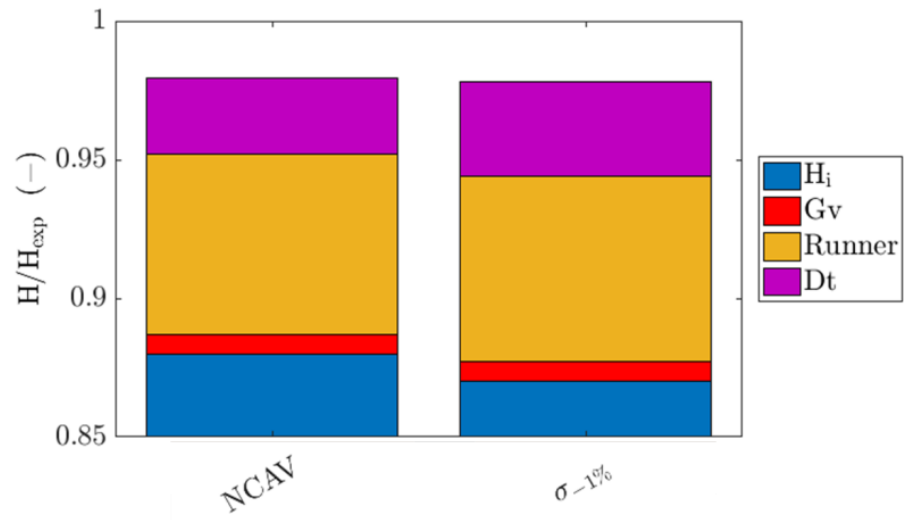

(b)

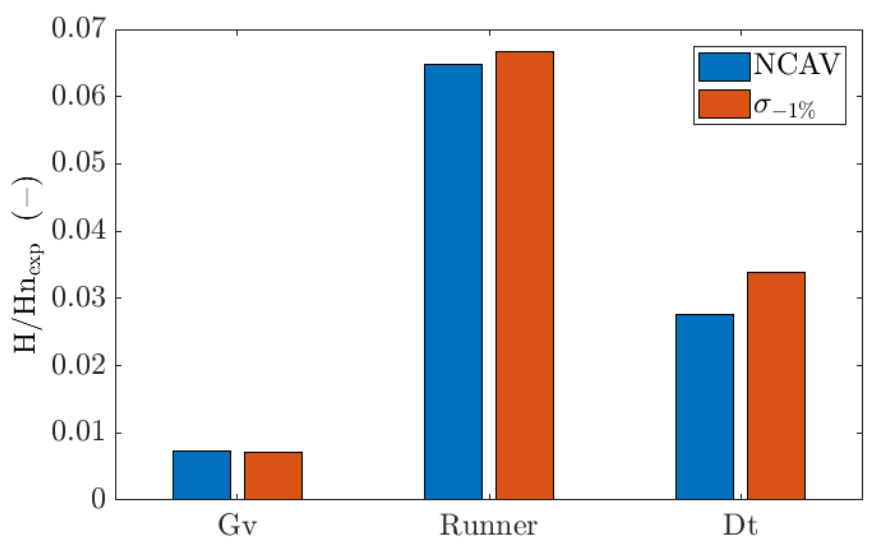

Fig. 9 Investigation of (a) the $\mathrm{H}$ and (b) the losses imposing Ptot on the inlet of $\mathrm{D}_{2}$ in the first (NCAV) and in the last $\left(\sigma_{-1} \%\right)$ point of the $\sigma$-break curve. 
The losses in the guide vanes $\Delta_{\mathrm{los}}{ }^{\mathrm{GV}}$ are almost the same in the two conditions. This means that the cavitation does not affect the flow in the guide vanes ring. In the runner the losses increase from $6.5 \%$ in non-cavitating conditions to the $6.8 \%$ at $\sigma_{-1} \%$. Consequently to the cavitation development, the losses increase of $0.8 \%$ also in the draft tube.

Focusing on the runner, in order to evaluate the global losses in this component of the machine, three cutting planes have been created (Fig. 10). The part between the $\mathrm{C}$ and the $\mathrm{D}$ surface is the leading edge of the blade (LE) while the part comprised between the $\mathrm{D}$ and the E planes is the trailing edge (TE).

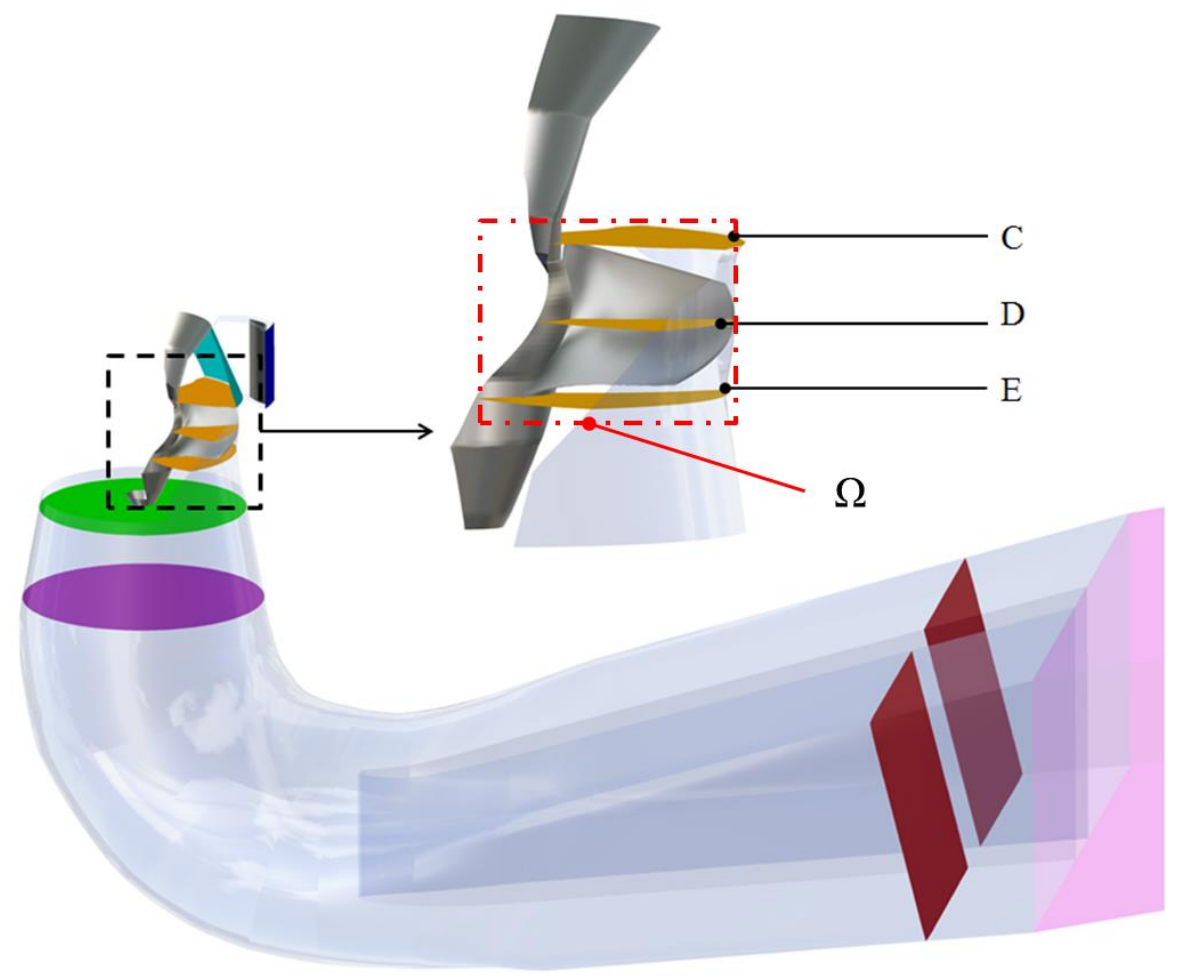

Fig. 10 Cutting surfaces defined for the runner losses analysis. C is near the leading edge, D is near the middle of the blade and $\mathrm{E}$ is near the trailing edge.

The histogram in Fig. 11 shows that with the Thoma number reduction the losses decrease on the leading edge part while increase on the trailing edge part. The losses can be estimated also by means of the local losses. The local losses can be divided into two contributions: the losses due to the shear stress and the losses due to the viscous dissipation. Considering that the shear stress term is negligible compared to the viscous dissipation term, only the dissipation losses (including turbulence model effects) have been considered in this analysis.

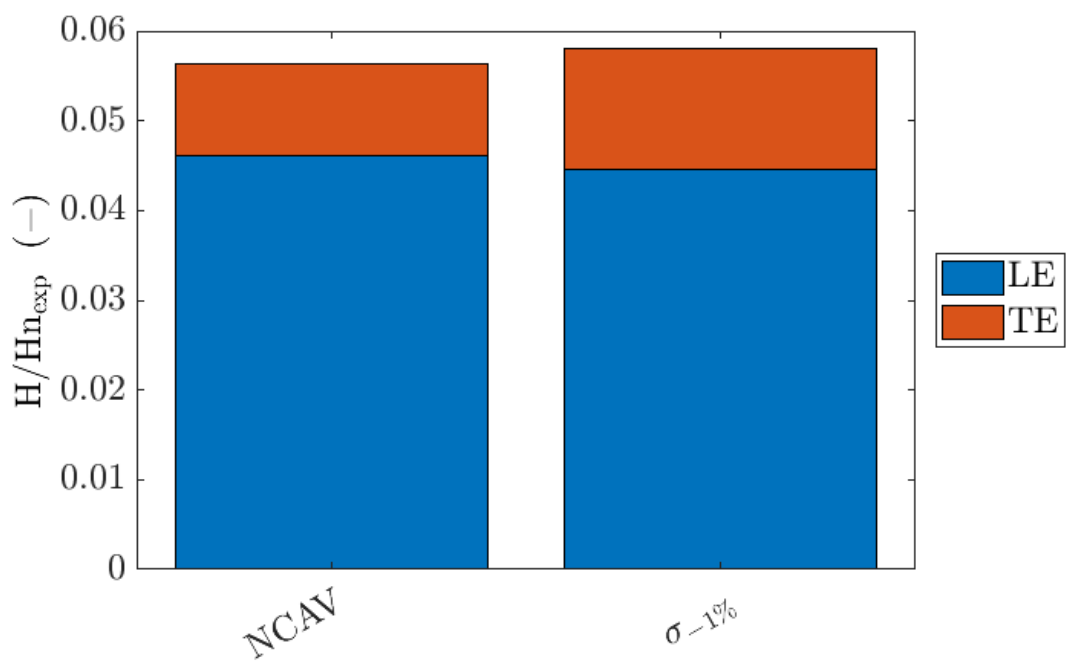

Fig. 11 The losses on the runner blade computed in non-cavitating conditions and at $\sigma_{-1 \%}$, shared between the leading edge (LE) and the trailing edge (TE). 
The dissipation losses in a rotating frame of reference, integrated on the control volume $\Omega$, are defined as:

$$
\Delta_{\text {los }}^{\text {dis }}=\frac{1}{\rho g Q} \iiint_{\Omega} \overline{\bar{\tau}}: \overline{\bar{\nabla}}(\vec{w}) d \Omega
$$

In eq. (10), $\overline{\bar{\tau}}$ is the tensor of the average viscous and turbulent stress and can be defined as:

$$
\overline{\bar{\tau}}=2\left(\mu+\mu_{T}\right) \overline{\bar{S}}
$$

where $\mu$ is the mixture viscosity, $\mu_{\mathrm{T}}$ is the turbulent viscosity and $\overline{\bar{S}}$ is the tensor of the deformation rates.

The difference between the dissipation losses computed at $\sigma_{-1} \%$ and in non-cavitating conditions is plotted in Fig. 12 by using iso-value surfaces.

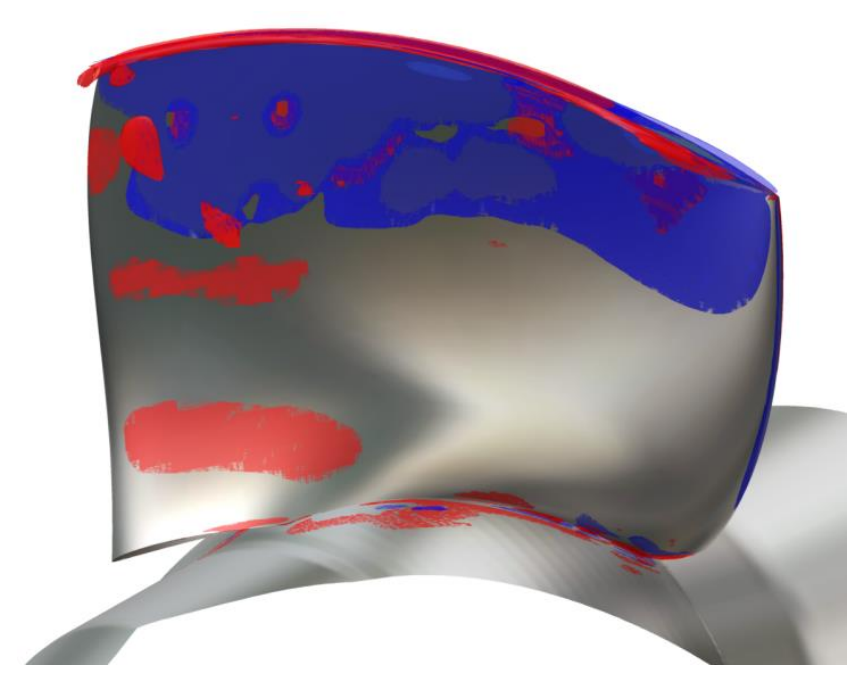

Fig. 12 Iso-value surfaces of the difference of losses due to the dissipation $\Delta^{\text {dis }}$ los in the runner in non-cavitating conditions and at $\sigma_{-1 \%}$, plotted on the runner blade.

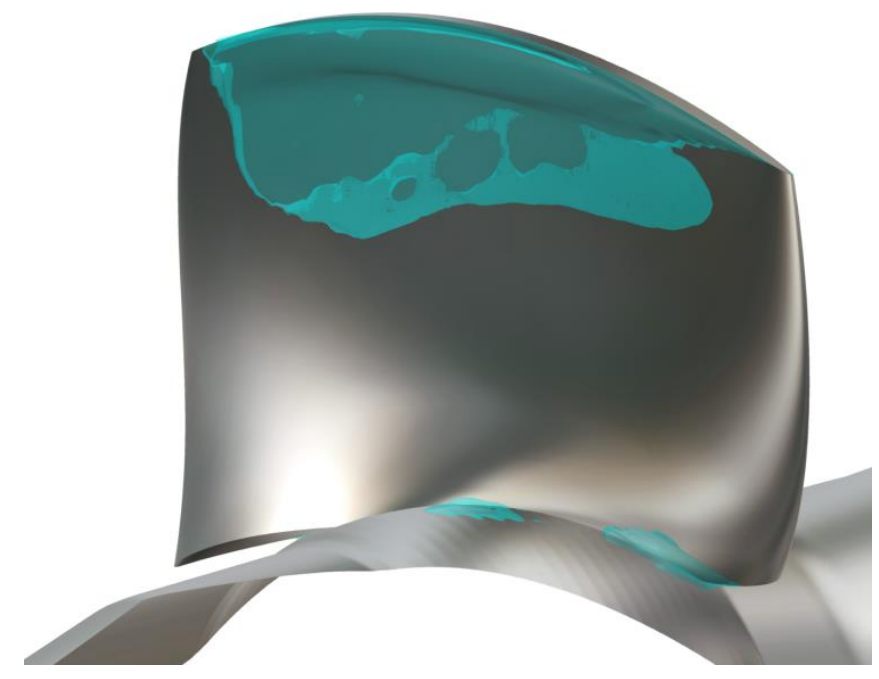

Fig. 13 Computed iso-surfaces of density $\left(\rho=980 \mathrm{~kg} / \mathrm{m}^{3}\right)$ at $\sigma_{\mathrm{S}}=0.55$

The red surfaces are the regions where the losses have been increased while the blue surfaces represent the zones where the losses have been decrease with the development of the cavitation phenomena. The red surfaces are mostly located on the hub and on the shroud regions. Near the shroud gap, the losses increase mostly close to the trailing edge. The blue surfaces are concentrated on the profile and on the tip of the blade. In the shroud gap region, the losses reduce close to the leading edge.
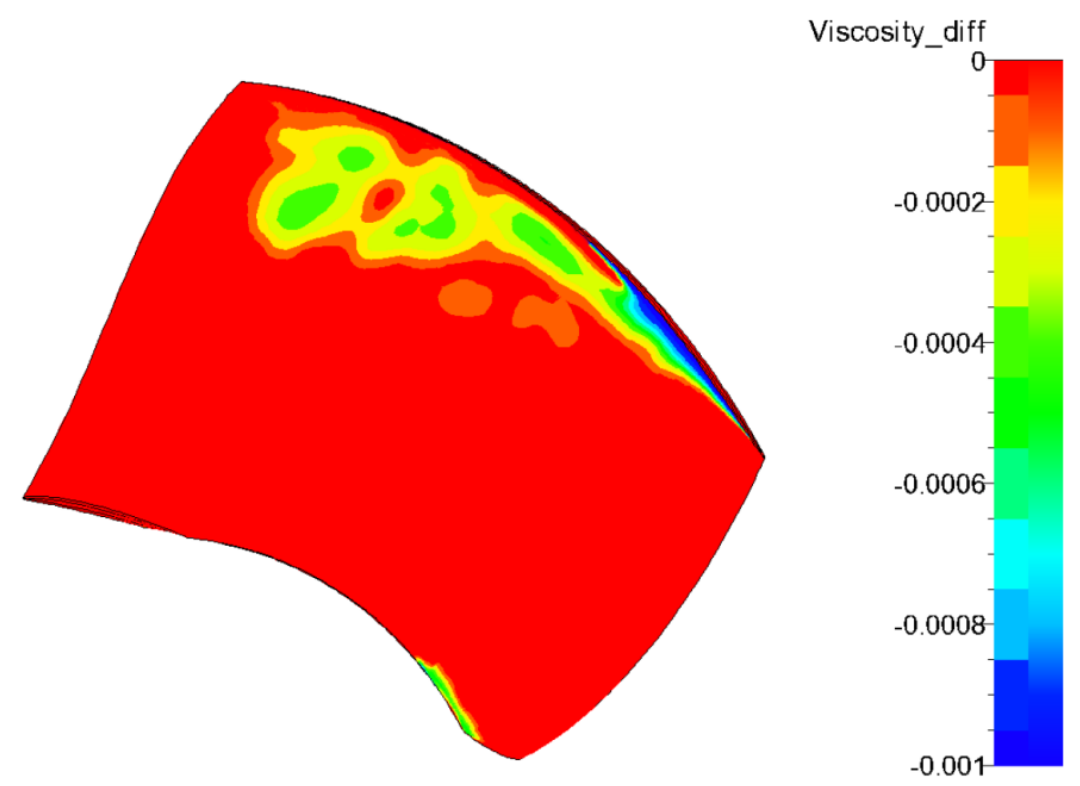

Fig. 14 The difference of $\left(\mu+\mu_{\mathrm{T}}\right)$ computed in the runner in non-cavitating conditions and at $\sigma_{-1 \%}$, plotted on the runner blade. 
According to the histogram in Fig. 11, as a consequence of the presence of the cavities structures, the losses decrease near the leading edge and increase close to the trailing edge. The extension of the blue zones (the regions of the losses reduction) is very similar to the shape of the computed vapor structures at $\sigma_{-1} \%$ (Fig. 13). The red surfaces are mostly concentrated near the shroud gap in a region characterized by strong flow recirculation.

The term of dissipation is function of the viscosities and of the gradient of flow velocity. In the vapor regions, $\left(\mu+\mu_{\mathrm{T}}\right)$ decreases and, consequently, the losses due to the dissipation will reduce. Indeed, plotting the difference of $\left(\mu+\mu_{\mathrm{T}}\right)$ computed at $\sigma_{-1}$ and in non-cavitating conditions (Fig. 14) it is evident that the most negative difference value regions are almost in the same position of the blue surfaces plotted in Fig. 12. On the contrary, near the blade tip, the presence of the gap on the shroud produces huge velocity gradients, due to the increase of the pressure difference between the pressure and the suction side of the blade, causing a consequentially augmentation of the dissipation losses term.

\section{Conclusion}

The aim of the present work was to develop a numerical methodology to predict the cavitation phenomena occurring in a Kaplan turbine and their in influence on the machine performances. Three-dimensional RANS equations were solved on two computational domains testing different sets of boundary conditions. Cavitation was included in simulations by a homogeneous approach coupled with a barotropic state law. Comparing the numerical results with available experimental data, a reliable computational strategy was finally proposed.

The first step of the methodology was to ensure a correct numerical reproduction of the turbine operating point in non-cavitating conditions, targeting the measured torque value. An iterative procedure was carried out on a simplified computational domain (including a single periodic interblades guide vane/runner/cone channel) to find the inlet mass flow rate value allowing to reduce the mismatch between experimental and numerical torque. Afterwards, the draft tube was included in the domain and cavitating simulations were performed comparing two inlet conditions: the discharge and the total pressure. The change of the inlet boundary condition led to improve the methodology, maintaining a constant head along the $\sigma$-break curve, as during experimental tests. The results obtained considering the torque evolution, the $\sigma$-break curve and the vapor structures development appeared in a wellagreement with experimental data. At smallest values of the $\sigma$, the cavitating flow becomes unstable, and the steady approach presented in this article is no longer adequate. Unsteady simulations are in progress to improve the prediction and the analy ses of more developed cavitating regimes.

Finally, by means of the losses analysis the regions of the runner blade where the dissipation losses increase and decrease in cavitation regime are identified. This allows to better understand the mechanism of the performances reduction with the cavitation structures development. Investigations of the dissipation losses in the draft tube could be performed in order to analyze the cavitation flow effects also in this part of the machine.

\section{Acknowledgments}

The present work was funded by a French FUI grant. The authors acknowledge GE Renewable Energy (Grenoble, France) for providing experimental data and technical support. Authors would also to thank Remi Lestriez of Numiberica for his huge contribution to this work.

\section{Nomenclature}

$\begin{array}{ll}A_{\min } & \text { Barotropic law slope }[\mathrm{Pa}] \\ c_{\min } & \text { Minimal speed of sound }[\mathrm{m} / \mathrm{s}] \\ g & \text { Gravitational acceleration }\left[\mathrm{m} / \mathrm{s}^{2}\right] \\ H & \text { Turbine net head }[\mathrm{m}] \\ H_{i} & \text { Turbine internal head }[\mathrm{m}] \\ P & \text { Static pressure }[\mathrm{Pa}] \\ P_{v} & \text { Vaporization pressure }[\mathrm{Pa}] \\ P_{t o t} & \text { Total pressure }[\mathrm{Pa}] \\ Q & \text { Mass flow rate }[\mathrm{kg} / \mathrm{s}] \\ R & \text { Reference radius }[\mathrm{m}] \\ S & \text { Machine cross-sections }\left[\mathrm{m}^{2}\right]\end{array}$

$\begin{array}{ll}T & \text { Toque [Nm] } \\ W & \text { Relative velocity [m/s] } \\ y^{+} & \text {Dimensionless wall distance [-] } \\ \alpha & \text { Void fraction [-] } \\ \mu & \text { Mixture viscosity }[\mathrm{Pa} \mathrm{s}] \\ \mu_{T} & \text { Turbulent viscosity }[\mathrm{Pa} \mathrm{s}] \\ \rho & \text { Mixture density }\left[\mathrm{kg} / \mathrm{m}^{3}\right] \\ \rho_{L} & \text { Liquid density }\left[\mathrm{kg} / \mathrm{m}^{3}\right] \\ \rho_{V} & \text { Vapor density }\left[\mathrm{kg} / \mathrm{m}^{3}\right] \\ \sigma & \text { Thoma number }[-] \\ \omega & \text { Rotational speed }[\mathrm{rad} / \mathrm{s}]\end{array}$

\section{References}

[1] J. Delannoy and Y. Kueny, "Two phase flow approach in unsteady cavitation modelling," Cavitation and Multiphase Flow Forum, ASME-FED, vol. 98, pp. 153-158, 1990.

[2] A. Singhal, N. Vaidya and L. A.D., "Multi-dimensional simulation of cavitating flows using a PDF model for phase change," ASME FEDSM, no. 97-3272, 1997.

[3] P. Zwart, A. Gerber and T. Belamri, "A two-phase flow model for predicting cavitation,” in Proc. of 5th Int. Conf. on Multiphase Flow, Yokohama, Japan, 2004.

[4] S. Leguizamón, C. Ségoufin, P. Hai-Trieu and F. Avellan, “On the Efficiency Alteration Mechanisms Due to Cavitation in Kaplan Turbines,” ASME. J. Fluids Eng., vol. 139(6), pp. 061301-061301-8, 2017. 
[5] D. Jošt, M. Morgout, A. Škerlavaj and E. Nobile, "Cavitation prediction in a Kaplan turbine using standard and optimized model parameters," in Conference: 6th IAHR International Meeting of the Workgroup on Cavitation and Dynamic Problems in Hydraulic Machinery and Systems, Ljubljana, Slovenia, 2015.

[6] M. Ishii and T. Hibiki, Thermo-Fluid Dynamics of Two-Phase Flow, New York: Spring-Verlag, 20111.

[7] O. Coutier-Delgosha, R. Fortes-Patella, J. Reboud, M. Hofmann and B. Stoffel, "Experimental and numerical studies of a centrifugal pump with two-dimensional curved blades in cavitating conditions," J. of Fluids Engineering, vol. 125/6, pp. 970-978, 2003.

[8] B. Pouffary, R. Fortes-Patella, J.-. L. Reboud and P.-A. Lambert, "Numerical Analysis of Cavitation Instabilities in Inducer Blade Cascade," ASME. J. Fluids Eng., vol. 130, pp. 041302-041302-8, 2008.

[9] U. Ješe, R. Fortes-Patella and S.Antheaume, "High head pump-turbine: Pumping mode numerical simulations with a cavitation model for off-design conditions," IOP Conf. Ser.: Earth Environ. Sci., vol. 22, p. 032048, 2014.

[10] J.-. L. Reboud, B. Stutz and O. Coutier- Delgosha, "Two-phase flow structure of cavitation: experiment and modelling of unsteady effects," in Proc. 3rd Internationl Symposium on Cavitation CAV1998, Grenoble, France, 1998.

[11] R. Fortes-Patella and E. Goncalves, "Numerical Simulation of Cavitating Flows with Homogeneous Models," Computers \& Fluids, vol. 38, pp. 1682-1696, 2009.

[12] F. Menter, M. Kuntz and R. Langtry, “Ten years of industrial experience with the SST turbulence model," Heat and Mass Transfer, vol. 4, 2003.

[13] NUMECA International, Theoretical manual FINE/Turbo v13.1, 2018. 